\title{
An Awareness Survey on the Protection and Use of Personal Health Information Focused on Applicants for Copies of the Medical Record
}

\author{
Eun-mi Choi ${ }^{1}$, Sun-won $\mathrm{Seo}^{2}$, Woo-sung Park ${ }^{3}$, Mee Jeong Lee ${ }^{3}$, \\ Yea-eun Kim ${ }^{2}$, Ok-nam $\mathrm{Kim}^{4}$ \\ Dept. of Healthcare Management, Kwandong Univ. ${ }^{1}$, \\ Dept. of Medical Information, Dankook Univ. Hospital ${ }^{2}$, \\ Dept. of Pediatrics, Dankook Univ. College of Medicine ${ }^{3}$, \\ Dept. of Prevention Medicine, The Catholic Univ. of Korea ${ }^{4}$
}

\begin{abstract}
Objective: To supplement a previous study on the management of medical records with a view to preparing a system capable of ensuring basic patient rights regarding the protection of confidential medical information. The study objectives are to provide detailed guidelines to regulate the access and protection of medical information by analyzing patients' understanding and views regarding the dissemination of medical records. Methods: A self-administered questionnaire was administered to 781 patients who visited five University hospitals located in Seoul, Busan, Gyeonggi, Chungnam and Jeonnam from July to September, 2008 and asked for copies of medical records to be issued. Data were analyzed by using the statistical program SPSS 13.0. Results: More than $70 \%$ of respondents wanted to access their medical records after confirming the required documents. The highest distribution in the range of persons able to receive copies of medical records without the individual patient's consent or required documents was 'only personally' in each variable. Copies of medical records were issued mostly within 1 hour, while the appropriate time of issuing the copies was within one day. Half of respondents approved of a subscription system that did not require a doctor consultation. The results regarding changes in the ways to request/issue copies of medical records to improve the convenience for applicants differed significantly according to age. Conclusion: Considering the sensitivity of personal health information, medical records should only be issued with the patient's consent and by confirming the identity of the designated person with required documents. Furthermore, people should be aware of the importance of protecting personal health information, and medical institutes should inform the requirements for bringing the relevant documents. Medical institutes play an important role in protecting personal records, which necessitates generalized guidelines. (Journal of Korean Society of Medical Informatics 15-3, 285-292, 2009)
\end{abstract}

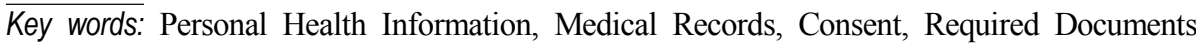

\footnotetext{
Received for review: July 2, 2009; Accepted for publication: August 20, 2009

Comesponding Author: Eun-mi Choi, Department of Healthcare Management, Kwandong University, Naegok-dong, Gangreung 210-701, Korea

Tel: +82-33-649-7583, Fax: +82-33-642-7723, E-mail: smart609@empal.com

*This study was supported by a grant of the Korea Health 21 R\&D Project, Ministry of Health \& Welfare, Republic of Korea (: A050909).

DOI:10.4258/jksmi.2009.15.3.285
} 


\section{Introduction}

Medical records mean the documents recording the particulars about health and disease-related information, which contain various types of examinations, treatments and result provided to patients by medical institutes. Data types include electronic materials or visual data originating in hospitals, and personal identification information such as name, address, phone number, and resident registration number (RRN). These act to support the physicians' diagnosis and treatment of patients and ensure the continuance of treatments ${ }^{1)}$. It is necessary to fulfill the treatments and prepare the unexpected symptoms. To complete the medical record is a duty of medical doctors, and the hospitals should preserve medical records for a certain period of time.

Medical records are used for various purposes-public/ private insurance claims, issuing health certificates, and juristic acts such as medical malpractice suits especially in case of excuses at the time of post-treatment ${ }^{2}$. Therefore, requests to issue copies of medical records have increased recently. According to the relevant regulations, medical institutes should provide copies of medical records to patients on request. If a third party requests the patient's copies of medical records, after identifying the identity and confirming the required document, it could be issued ${ }^{3)}$.

The important procedures of issuing the copies are patient's consent and the required documents, no adequate guidelines exist. Regulations related to issuing the copies in other countries are as follows.

In the New York hospital in the United States, in order to read and copy the medical records, the individual should submit a written application to the Health Information Management Services or other related departments. The medical institute notifies the individual of the procedures for requesting the copies, costs related to copies and delivery and the reasons to deny a request under certain conditions ${ }^{4}$.

In the case of Illinois hospital in the United States, information on medical records about treatments, payments and operations management in health care can be issued. If "Designated data sets" that limited only into information necessary to make decisions relating to treatment are applied to be open, any violation or underlying violation should be reported to the privacy officer. The types and ranges of the provided information can be understood through the procedure. The department of health information operates the procedures of written authorization, HIPAA requirement, review records, costs, application papers and preservation of recording lists. For 30 days before copying, the records should be reviewed carefully ${ }^{5}$. An applicants must pay a cost-based fee. The basic fee to copy of a patient's medical records is $\$ 22.84$ (about 29,000 won in 2009), and changes according to various state laws by periods. This includes the labor costs of searching, copying or scanning medical records, to update system for records, and delivery and preparing for copies?).

In Japan, the law for the principles of protecting personal information require to the patient's consent in case of using personal information and providing personal data to a third party ${ }^{7}$.

In Canada, when a patient requires access to his/her personal health information, the manager of health information should provide copies of medical records to the patient with an explanation about the terms used in records such as codes and abbreviations ${ }^{8}$.

This study provides supplementary and basic data to overcome the insufficiency of the previous studies on the management conditions of medical records in medical institutes in order to prepare for a system to ensure human rights of information". In addition, it provides quantitative grounds to prepare for a detailed guideline for copies through an awareness survey of applicants about the protection and use of personal health information.

The detailed purposes of this study are as follows.

1) Identify the general characteristics regarding is- 
suing the copies of medical records.

2) Describe the protection and use of the personal health information related to consent and the required documents.

3) Understand the actual conditions of issuing the copies and relevant awareness.

\section{Materials and Methods}

For the study, a self-administered questionnaires was administered to 781 patients who visited five University hospitals located in Seoul, Busan, Gyeong-gi, Chungnam and Jeon-nam from July to September in 2008 and asked for copies of their medical records.

The questionnaire was independently developed by researchers using the results of previous studies about protecting and using personal health information in hospitals analyzing the literatures such as domestic and overseas regulations and international standards and through the experts' evaluation ${ }^{10-12}$.

The questionnaire consisted of three parts as follows.

First, the general characteristics of people requesting copies of medical records were identified according to various categories of sex, age, experience of issuing copies (frequency: no, one time, two times, more than 3 times), relationship with patient (patient, family mem- bers, legal representative, private/public insurance party) and purpose of issuing the copies (insurance claims, other hospitals treatment, court of law submit, military administration, public institution, personal archive).

Second, to elucidate the protection and use of the personal health information, it was investigated that providing and using of health information under the condition of no required documents and unknown to patients and the range of person being able to take the copies of medical records without patients' consent or required documents.

Third, to understand the actual conditions of copy issuance and relevant awareness, we investigated the actual time of copying the medical records, appropriate time for issuing the copies, operating the subscription system and procedure to request/issue copies of medical records.

Data were analyzed by using the statistic program SPSS 13.0. Frequency analysis was used for general characteristics, and the multiple-choice analysis and t-test were used for the contents of medical records.

Table 1. General characteristics

\begin{tabular}{|c|c|c|c|c|c|}
\hline Variable & Response & $(\%)$ & Variable & Response & $(\%)$ \\
\hline Sex & & & Relation with patient & & \\
\hline Male & 380 & 49.9 & Patient & 526 & 69.7 \\
\hline Female & 382 & 50.1 & Family members & 176 & 23.3 \\
\hline Age & & & Legal representative & 18 & 2.4 \\
\hline $20-29$ & 169 & 23.9 & Private insurance party & 29 & 3.8 \\
\hline $30-39$ & 195 & 27.5 & Public insurance party & 2 & 0.3 \\
\hline $40-49$ & 199 & 28.1 & Others & 4 & 0.5 \\
\hline $50-59$ & 112 & 15.8 & Purpose of issuing the copies & & \\
\hline$\geq 60$ & 33 & 4.7 & Insurance claims & 369 & 47.2 \\
\hline Experienced issuing the copies & & & Other hospitals treatment & 238 & 30.5 \\
\hline No & 474 & 60.7 & Court of law submit & 23 & 2.9 \\
\hline 1 & 170 & 21.8 & Military administration & 65 & 8.3 \\
\hline 2 & 76 & 9.7 & Public institution & 51 & 6.5 \\
\hline$\geq 3$ & 61 & 7.8 & Personal archive & 35 & 4.5 \\
\hline Total & & & & 781 & 100.0 \\
\hline
\end{tabular}




\section{Results}

\section{General characteristics}

To define the respondents, several socio-demographic characteristics were evaluated such as sex, age, experiences of issuing copies, relationship with patient, and purpose of issuing the copies (Table 1). The respondents consisted of $380(49.9 \%)$ males and 382 (50.1\%) females. Most applicants were economically active people aged between 20 and 60 and $60.7 \%$ were making the request for the first time. However 61 people $(7.8 \%)$ had experienced copying medical records more than three times.

The relationship of the applicant with the patient were the patient himself/herself 526 (69.7\%), family members 176 (23.3\%), legal representative 18 (2.4\%), private insurance party 29 (3.8\%), public insurance party $2(0.3 \%)$, others $2(0.5 \%)$.

The purpose of issuing the copies were for insurance claims 369 (47.2\%), other hospital treatment 238 (30.5\%), court of law submit $23(2.9 \%)$, military administration $51(6.5 \%)$, public institution $51(6.5 \%)$, and personal archive 35 (4.5\%).

\section{Awareness of providing and using of health} information under the condition of no required documents and unknown to patients

Most people replied that their medical records should only be copied by restricted person who have the re- quired documents with their consent. The response was similar in the categories of sex and experienced issuing copies. The rate of females replying as "limited people only after confirming the required documents" at $80.7 \%$ was higher than that of males at $77.6 \%$. People who experienced issuing the copies more than one time replied as 'confirming the required documents' at a higher rate than those with no experience. More males $(8.0 \%)$ answered as "do not care" than females $(3.5 \%)$, the rates of rely as "do not control" were the highest in those in their 20s (Table 2).

\section{The range of persons able to take the copies of medical records without patients' consent or required documents}

In the result of the multiple choice questions about people who can get the copies of medical records without the patient's consent or required documents, although the percentages varied, 'it could be issued only personally' was the highest distribution in each variable.

Regarding spouse, more females (without consent, $36.1 \%$ /without required documents, $39.3 \%$ ) than males (without consent $31.6 \%$, without the required documents $33.4 \%$ ) answered that they could provide the copies to spouse. The rates of respondents over the age of 60 years who could provide their copies of medical record to spouse had a higher distribution than in the other age groups without consent 17 (51.5\%) and without required documents 18 (54.5\%) respectively.

Compared to the other age groups, the rates in the

Table 2. Awareness of providing and using health information under the condition of no required documents and unknown to patients

\begin{tabular}{|c|c|c|c|c|c|c|c|}
\hline \multirow{2}{*}{ Variable } & \multicolumn{2}{|c|}{ Sex } & \multicolumn{5}{|c|}{ Age } \\
\hline & Male & Female & $20-29$ & $30-39$ & $40-49$ & $50-59$ & $\geq 60$ \\
\hline Do not care & $30(8.0)$ & $13(3.5)$ & $5(3.0)$ & $9(4.7)$ & $11(5.6)$ & $10(9.2)$ & $3(9.4)$ \\
\hline Do not control & $54(14.4)$ & $59(15.8)$ & $33(19.5)$ & $31(16.3)$ & $27(13.8)$ & $12(11.0)$ & $1(3.1)$ \\
\hline Confirm the required documents & $290(77.5)$ & $302(80.7)$ & $131(77.5)$ & $150(78.9)$ & $158(80.6)$ & $87(79.8)$ & $28(87.5)$ \\
\hline Total & $374(100.0)$ & $374(100.0)$ & $169(100.0)$ & $190(100.0)$ & $196(100.0)$ & $109(100.0)$ & $32(100.0)$ \\
\hline$p$-value & & $7.19^{*}$ & & & & & 13.07 \\
\hline
\end{tabular}


twenties age group answered 'it could be issued to parents' was high, without consent 70 (41.4\%), and without required documents 69 (40.8\%).

Compared with sons (daughters) and sons-in-law (daughters-in-law), the rates of the respondents who could provide to sons-in-law (daughters-in-law) were relatively lower than sons (daughter) in both sexes and all age groups (Table 3).

Table 3. The range of persons able to take copies of medical records without patients' consent/required documents

\begin{tabular}{|c|c|c|c|c|c|c|c|}
\hline \multirow{2}{*}{ Variable } & \multicolumn{2}{|c|}{ Sex } & \multicolumn{5}{|c|}{ Age } \\
\hline & Male & Female & $20-29$ & $30-39$ & $40-49$ & $50-59$ & $\geq 60$ \\
\hline \multicolumn{8}{|l|}{ Without consent } \\
\hline Only personally & $199(52.4)$ & $186(48.7)$ & $79(46.7)$ & $99(50.8)$ & $105(52.8)$ & $61(54.5)$ & $12(36.4)$ \\
\hline Spouse & $120(31.6)$ & $138(36.1)$ & $47(27.8)$ & 65 (33.3) & $72(36.2)$ & $42(37.5)$ & $17(51.5)$ \\
\hline Children & 80 (21.1) & 91 (23.8) & $34(20.1)$ & $47(24.1)$ & $51(25.6)$ & $25(22.3)$ & $7(21.2)$ \\
\hline Children's spouse & $31(8.2)$ & $17(4.5)$ & $8(4.7)$ & $15(7.7)$ & $16(8.0)$ & $5(4.5)$ & $1(3.0)$ \\
\hline Parents & $103(27.1)$ & 89 (23.3) & $70(41.4)$ & $51(26.2)$ & 38 (19.1) & $14(12.5)$ & $7(21.2)$ \\
\hline Brothers and sisters & $48(12.6)$ & $36(9.4)$ & $24(14.2)$ & $23(11.8)$ & $24(12.1)$ & $7(6.3)$ & $1(3.0)$ \\
\hline Legal representative & $29(7.6)$ & $32(8.4)$ & $17(10.1)$ & $17(8.7)$ & $15(7.5)$ & $6(5.4)$ & $1(3.0)$ \\
\hline Managerof asylum & $10(2.6)$ & $7(1.8)$ & $3(1.8)$ & $4(2.1)$ & $5(2.5)$ & $1(0.9)$ & $1(3.0)$ \\
\hline \multicolumn{8}{|c|}{ Without the required documents } \\
\hline Only personally & $186(48.9)$ & $160(41.9)$ & $84(49.7)$ & $91(46.7)$ & 81 (40.7) & $59(52.7)$ & $10(30.3)$ \\
\hline Spouse & $127(33.4)$ & $150(39.3)$ & $40(23.7)$ & $67(34.4)$ & $90(45.2)$ & $39(34.8)$ & $18(54.5)$ \\
\hline Children & $76(20.0)$ & $95(24.9)$ & $22(13.0)$ & $53(27.2)$ & $51(25.6)$ & $23(20.5)$ & $9(27.3)$ \\
\hline Children's spouse & $37(9.7)$ & $21(5.5)$ & $5(3.0)$ & $17(8.7)$ & $16(8.0)$ & $10(8.9)$ & $3(9.1)$ \\
\hline Parents & $92(24.2)$ & $92(24.1)$ & $69(40.8)$ & $54(27.7)$ & $35(17.6)$ & $9(8.0)$ & $6(18.2)$ \\
\hline Brothers and sisters & $38(10.0)$ & $32(8.4)$ & $20(11.8)$ & $24(12.3)$ & $15(7.5)$ & $5(4.5)$ & $1(3.0)$ \\
\hline Legal representative & $22(5.8)$ & $20(5.2)$ & $4(2.4)$ & $14(7.2)$ & $13(6.5)$ & $6(5.4)$ & $1(3.0)$ \\
\hline Managerof asylum & $6(1.6)$ & $7(1.8)$ & $2(1.2)$ & $4(2.1)$ & $5(2.5)$ & $0(0.0)$ & $0(0.0)$ \\
\hline
\end{tabular}

Table 4. Time of copies of medical records

\begin{tabular}{|c|c|c|c|c|c|c|c|}
\hline \multirow{2}{*}{ Variable } & \multicolumn{2}{|c|}{ Sex } & \multicolumn{5}{|c|}{ Age } \\
\hline & Male & Female & $20-29$ & $30-39$ & $40-49$ & $50-59$ & $\geq 60$ \\
\hline \multicolumn{8}{|l|}{ Actual time } \\
\hline$\leq 1 \mathrm{hr}$ & $280(74.7)$ & 291 (77.2) & $134(79.3)$ & 147 (75.4) & $147(75.4)$ & 89 (81.7) & $24(77.4)$ \\
\hline $1-2 \mathrm{hr}$ & $77(20.5)$ & $78(20.7)$ & 31 (18.3) & $43(22.1)$ & $42(21.5)$ & $14(12.8)$ & 7 (22.6) \\
\hline $3-4 \mathrm{hr}$ & $15(4.0)$ & $5(1.3)$ & $2(1.2)$ & $4(2.1)$ & $6(3.1)$ & $4(3.7)$ & $0(0.0)$ \\
\hline $4-5 \mathrm{hr}$ & $2(0.5)$ & $0(0.0)$ & $1(0.6)$ & $0(0.0)$ & $0(0.0)$ & $0(0.0)$ & $0(0.0)$ \\
\hline $5 \mathrm{hr} \geq$ & $1(0.3)$ & $0(0.0)$ & $1(0.6)$ & $0(0.0)$ & $0(0.0)$ & $0(0.0)$ & $0(0.0)$ \\
\hline$\geq 24 \mathrm{hr}$ & $0(0.0)$ & $3(0.8)$ & $0(0.0)$ & $1(0.5)$ & $0(0.0)$ & $2(1.8)$ & $0(0.0)$ \\
\hline Total & $375(100.0)$ & $377(100.0)$ & $169(100.0)$ & $195(100.0)$ & $195(100.0)$ & $109(100.0)$ & $31(100.0)$ \\
\hline$p$ value & & $11.21^{*}$ & & & & & 20.44 \\
\hline \multicolumn{8}{|l|}{ Appropriate time } \\
\hline$\leq 1$ day & $290(76.5)$ & $280(73.5)$ & 134 (79.3) & 151 (77.4) & $145(73.2)$ & $88(78.6)$ & $26(81.3)$ \\
\hline$\leq 3$ day & $62(16.4)$ & $71(18.6)$ & $29(17.2)$ & $29(14.9)$ & 33 (16.7) & $19(17.0)$ & $3(9.4)$ \\
\hline$\leq 1$ week & $20(5.3)$ & $28(7.3)$ & $3(1.8)$ & $12(6.2)$ & $18(9.1)$ & $5(4.5)$ & $2(6.3)$ \\
\hline$\leq 1$ month & $7(1.8)$ & $2(0.5)$ & $3(1.8)$ & $3(1.5)$ & $2(1.0)$ & $0(0.0)$ & $1(3.1)$ \\
\hline Total & $379(100.0)$ & $381(100.0)$ & $169(100.0)$ & $195(100.0)$ & $198(100.0)$ & $112(100.0)$ & $32(100.0)$ \\
\hline$p$ value & & 4.89 & & & & & 13.73 \\
\hline
\end{tabular}




\section{Time for the copies of medical records}

More than $70 \%$ of the respondents could take copies of medical records within 1 hour in both sexes and all age groups, but fewer at over 5 hours and less than 24 hours.

For the questionnaire about the awareness of the appropriate time of issuing copies of medical records, most respondents wanted to take the copies within the day after their request, and less than $25 \%$ of respondents who replied within 3 or 7 days (Table 4).

\section{Awareness of operating the subscription system}

There were patient complaints about the waiting period to consult with a doctor in medical institutes, so we asked about the introduction of operating a subscription system and issuing copies of medical records at a certain period after requesting copies of medical records without consultation with a doctor.

The rates of agreeing with operating a subscription system for issuing the copies were higher in females $(59.7 \%)$ than in males $(50.5 \%)$. For the purpose of insurance claims, other hospital treatments, malpractice suits and personal archives, the rates of agreeing with operatinga a subscription system without consultation with a doctor were higher than in other cases. On the other hand, for the purpose of military manpower administration and public institution, the rates of those opposed to operating a subscription system were higher (Table 5).

\section{Change the way to request/issue copies of medical records}

Results of the changing the way to request copies of medical records for the convenience of applicants were as follows. By age, the rate of 'request through direct visit' was the highest in those over sixty $(77.8 \%)$, followed by those in the fifties $(50.0 \%)$ and in the twenties $(44.8 \%)$. The rate of 'request through the mail' was high in the thirties (25.0\%) and forties (31.5\%), it was relatively higher than other age groups but not statistically significant. The rate of using electronic certificate on the web was the highest in the thirties $(52.8 \%)$.

The results of the change in the ways to issue copies of medical records to improve the convenience of applicants were statistically significant in sex and all age groups.

Both men and women mostly replied that they will visit in person and receive via mails when necessary, which was respectively a few as $178(47.5 \%)$ and 218

Table 5. Subscription system and the ways to issue copies of medical records

\begin{tabular}{|c|c|c|c|c|c|c|c|}
\hline \multirow{2}{*}{ Variable } & \multicolumn{2}{|c|}{ Sex } & \multicolumn{5}{|c|}{ Age } \\
\hline & Male & Female & $20-29$ & $30-39$ & $40-49$ & $50-59$ & $\geq 60$ \\
\hline \multicolumn{8}{|l|}{ Subscription system } \\
\hline Yes & $192(50.5)$ & $228(59.7)$ & $96(56.8)$ & $108(55.4)$ & $111(55.8)$ & $56(50.0)$ & $18(54.5)$ \\
\hline No & $188(49.5)$ & $154(40.3)$ & $73(43.2)$ & $87(44.6)$ & $88(44.2)$ & $56(50.0)$ & $15(45.5)$ \\
\hline Total & $380(100.0)$ & $382(100.0)$ & $169(100.0)$ & $195(100.0)$ & $198(100.0)$ & $112(100.0)$ & $32(100.0)$ \\
\hline$p$ value & & $6.46^{*}$ & & & & & 1.42 \\
\hline \multicolumn{8}{|c|}{ Ways to issue copies } \\
\hline Mail & 41 (10.9) & $45(12.1)$ & $14(8.3)$ & $25(13.0)$ & $21(10.8)$ & $10(9.4)$ & 7 (21.9) \\
\hline Mail/Directly & $178(47.5)$ & $218(58.4)$ & $102(60.4)$ & $112(58.0)$ & $101(51.8)$ & $43(40.6)$ & $13(40.6)$ \\
\hline Directly & $156(41.6)$ & $110(29.5)$ & $53(31.4)$ & $56(29.0)$ & $73(37.4)$ & $53(50.0)$ & $12(37.5)$ \\
\hline Total & $375(100.0)$ & $373(100.0)$ & $169(100.0)$ & $193(100.0)$ & $195(100.0)$ & $106(100.0)$ & $32(100.0)$ \\
\hline$p$ value & & $12.18^{*}$ & & & & & $21.71^{*}$ \\
\hline
\end{tabular}


(58.4\%). In age groups, the most respondents will visit in person and receive via mails when necessary as well. With increasing ages more respondents will visit in person for issuing copies, but more of those over sixty will receive copies via mail $(21.9 \%)$ than other age groups (Table 5).

\section{Discussion}

Of the surveyed patients, $77.5 \%$ of males and $80.7 \%$ of females did not want unauthorized access to their personal records. Unfortunately, many patients are not aware of their rights that protect their personal health information. More than $50 \%$ of respondents were particularly worried about unauthorized access. This highlights a culture not well versed in the protection of private health information.

Regarding who should be allowed to take copies of medical records without patients' consent or required documents, more than half of respondents answered 'it could be issued only personally' in all sexes and age groups. This indicated that they remained unaware of their privacy rights regarding the protection of personal health information. The awareness of their rights varied according to the age group. Respondents over 60 years of age were prepared to provide medical information to their spouses, whereas those in their twenties were prepared to provide medical information to their parents more readily than older groups. These results indicate a real gap in different age groups' preparedness to share medical information.

Compared with children and in-laws, the rate of the respondents who could provide copies to children's spouse was relatively lower, which indicated that children are more precious than children's spouses in Korean society and culture.

The extended family system with priority on the father as head of the family is prevalent in Korea. In consideration of family unity with comparison of gender, women are more closely related to their sons and daughters than their husbands, which was supported by a study finding that the lowest unity was with the parents-in- law ${ }^{13) 14}$. The long waiting period to consult with a doctor in medical institutes was one of the patients' complaints. To improve the applicants' convenience, $50.5 \%$ of males and $59.7 \%$ females agreed with operating a subscription system without consultation with a doctor. While there was a small gap between agreement and opposition, more women agreed to operate a subscription system. The results differed according to the purposes of issuing copies, and in case of an individual's need such as amendment, they want to consult with doctors directly.

Regarding the ways to request copies, those in their twenties and thirties groups want to request the copies through electronic certificate on the web, which was attributed to their working activities and high accessibility to the internet.

Regarding the ways to issue copies, both males and females, and those in their twenties, thirties and forties want to choose between direct visit and via mail as occasion. The rate of receiving copies via mail as taking risks was relatively low in both sexes and all age groups. Even considering the copy issuing (reservation) system and providing via mails, the rate of visiting in person and submitting the relevant documents for issuing the copies was high.

Considering the sensitivity of personal health information, medical records should be issued under patient's consent and by confirming a designated person with required documents. Furthermore, people should be aware of the importance of the protection of personal health information, and medical institutes should inform the requirements of bringing the relevant documents.

Medical institutes play an important role in protecting personal record, which necessitates the use of generalized guidelines that can be widely accepted among hospitals.

In addition, this study is expected to be used as basic data for increasing the awareness about protecting per- 
sonal health information and providing guidelines for medical institutes.

\section{REFERENCES}

1. Lee KH, Choi EM. Theory of Hospital Management. 1st ed. Seoul:Shingwang Publisher;2002. pp.411.

2. Seok HT. Medical Agreement II. 1st ed. Seoul:Judicial administration;1988. pp.67.

3. Assembly Health and Welfare, 2003;4.3(65507-275).

4. HIPAA Notice of Privacy Practices. Available at: http://www.nyhq.org.

5. University of Illinois Medical Center at Chicago: Management Policy and Procedure.:IM 4.01. 2005.5.

6. University of Illinois Medical Center at Chicago, 2007 Available at: http://www.lamblawoffice.com/medicalrecords-copying-charges.html\#Pennsylvania.

7. Ministry of Health, Labor and Welfare, Gaiho Guideline of Personal information protection for Medicine or nursing. Available at: http://www.mhlw.go.jp/seikatsu/ kojin/index http://www.mhlw.go.jp/shingi/ 2009.

8. Information and Privacy Commissioner/Ontario, Fre- quently Asked Questions: Health Information protection Act, Available at: www.ipc.on.ca.

9. Moon MM. Department of Public Health, Graduate School of Health Science Chosun University, Unpreparedness of the Required Documents and Related Factors When Issuing Copies of Medical Records -Focused on Tertiary Referral Hospital-, 2009. 2.

10. Center for interoperable EHR, Report of Development of Information Protection and Security System, 2007. 11; Available at: www.ehrkorea.org.

11. Office for Civil rights. Guidance explaining significant aspects of the privacy rule. December 4, 2002. Available at: www.hhs.gov/ocr/hipaa/privacy.html.

12. Hughes Gwen. Defining the Designated Record Set (AHIMA Practice Brief). Journal of AHIMA 2003; 74(1):64A-D.

13. Lee MS. Factors affecting the latent divorce intention among the women. Academy of Critical Social Welfare 2006;8(22):207-266.

14. Lee KJ, Byun WS, Kim HJ. A Comparative Study on the Family Consciousness Between Korea and Japan, Centered on Seoul and Fukuoka Department-. Korean Women's Development Institute 1992;50-51. 